\title{
Laterally Positioned Flap: A Simple and Successful Technique to Cover Isolated Recession of Miller Class-I
}

\author{
Dr. Shashi Kant Chaudhary, ${ }^{1}$ Dr. Harish Kumar Shah, ${ }^{1}$ Dr. Khushboo Goel, ${ }^{1}$ Dr. Sajeev Shrestha ${ }^{1}$ \\ ${ }^{1}$ Department Of Periodontology and Oral Implantology, \\ College of Dental Surgery, BP Koirala Institute of Health Sciences, Dharan, Nepal.
}

\begin{abstract}
Gingival recession is a common mucogingival deformity that brings aesthetic discomfort, hypersensitivity and inability to perform proper oral hygiene. LPF is the widely used technique to cover single recession of Miller Class-I and Class-II when adequate keratinized tissue exists adjacent to the recession. We report a case of 32-year-old female who presented with chief complaints of receding gum and sensitivity in lower front teeth region. Clinical examination revealed Miller's Class-I vertical recession with $4 \mathrm{~mm}$ depth on buccal aspect of left mandibular canine. LPF was planned and operated for the root coverage. After 6 months of therapy, 100\% root coverage was achieved with satisfactory healing and aesthetic was comparable to adjacent gingiva.
\end{abstract}

Keywords: Class-I recession; laterally positioned flap; root coverage.

\section{INTRODUCTION}

Gingival recession is defined as an apical migration of the gingival margin in relation to the cement-enamel junction. ${ }^{1}$ Gingival recession causes an imbalance between pink and white tissue that may result in aesthetic concern and hypersensitivity. It may be localised/generalised or associated with one/more tooth surfaces. Its aetiology is multifactorial that may include plaque-induced inflammation, calculus, iatrogenic restorations, trauma from tooth brushing, tooth malposition, high frenum attachment, and uncontrolled orthodontic movements. ${ }^{2}$ The most important factor increasing the risk of recession is the thin gingival biotype.

A variety of mucogingival surgeries have been suggested for root coverage. These surgical procedures can be classified as pedicle soft tissue grafts, free soft tissue grafts or a combination of these. ${ }^{1}$ The treatment of choice for recession coverage should address the biological as well as the patient's aesthetic demands. ${ }^{3}$

\section{Correspondence:}

Dr. Shashi Kant Chaudhary

Department Of Periodontology and Oral Implantology, College of Dental Surgery, BP Koirala Institute of Health Sciences, Dharan, Nepal.

email: shashi.tooth@gmail.com

\section{Citation}

Chaudhary SK, Shah HK, Goel K, Shrestha S. Laterally positioned flap: a simple and successful technique to cover isolated recession of Miller class-I. J Nepal Soc Perio Oral Implantol. 2017;1(2):78-80.

\section{CASE REPORT}

A 35-year-old female presented to the Department of Periodontology and Oral Implantology, CODS, BPKIHS, Dharan with chief complaints of receding gum and sensitivity in lower front teeth region. She was systemically healthy with no adverse habits. Intraoral examination revealed isolated recession on left mandibular canine (33) with reasonably good oral hygiene (Figure 1a). A vertical recession defect of $4 \mathrm{~mm}$ was apparent on the mid-buccal surface of 33 (Figure 1b). The base of the sulcus was coronal to the mucogingival junction and radiographic examination showed no bone loss interdentally. The keratinized tissue on the adjacent tooth was adequate. After phase I therapy, with patient's consent it was decided to surgically treat the case by the laterally positioned flap (LFP).
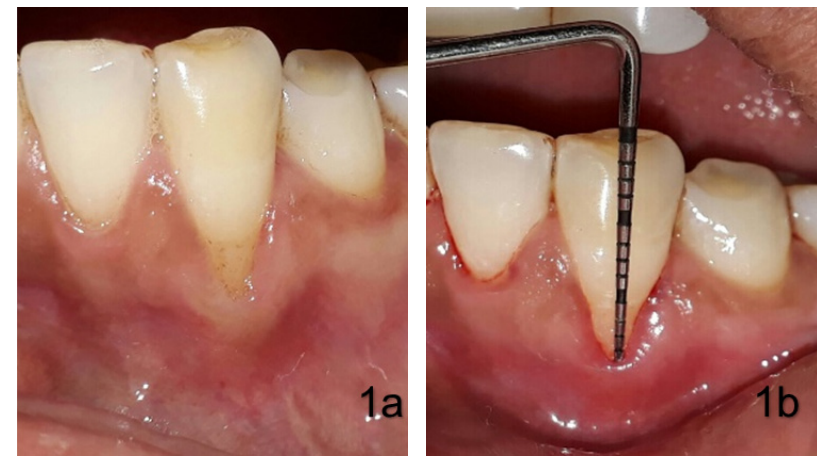

Figure 1a, 1b: Pre-operative view. 

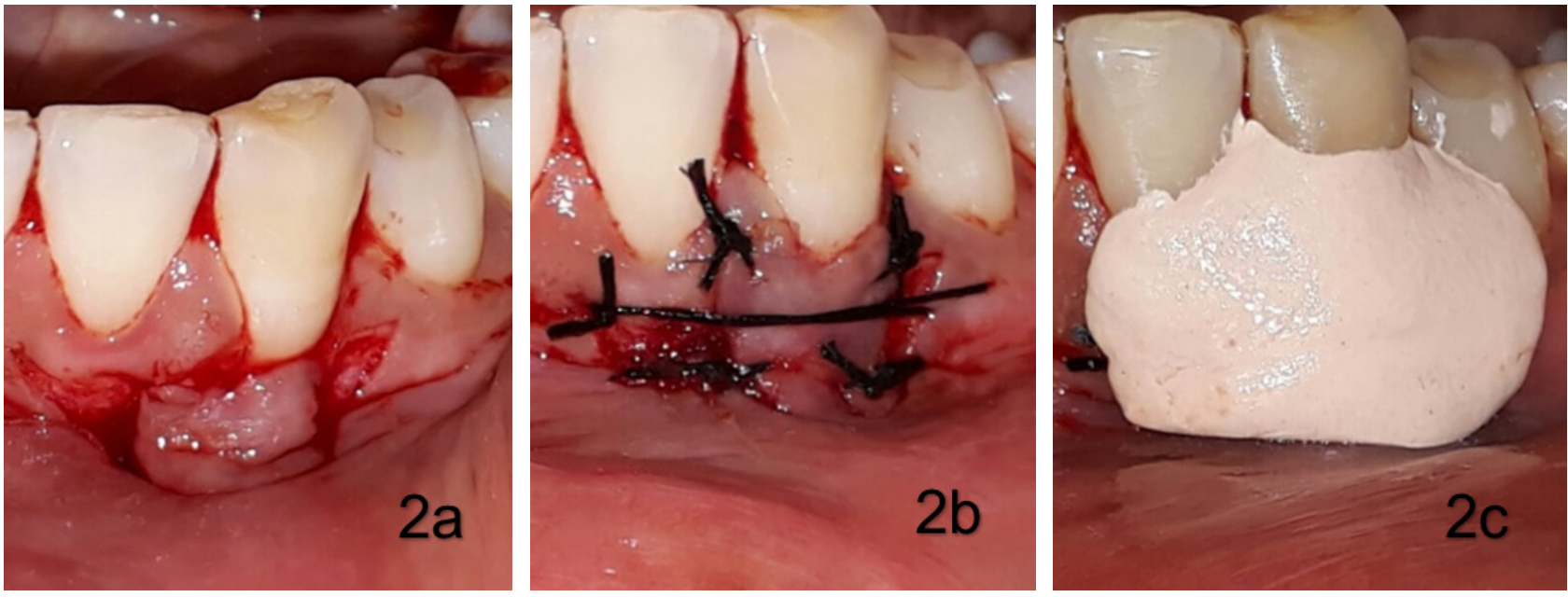

Figure 2a, 2b, 2c: Operative view.
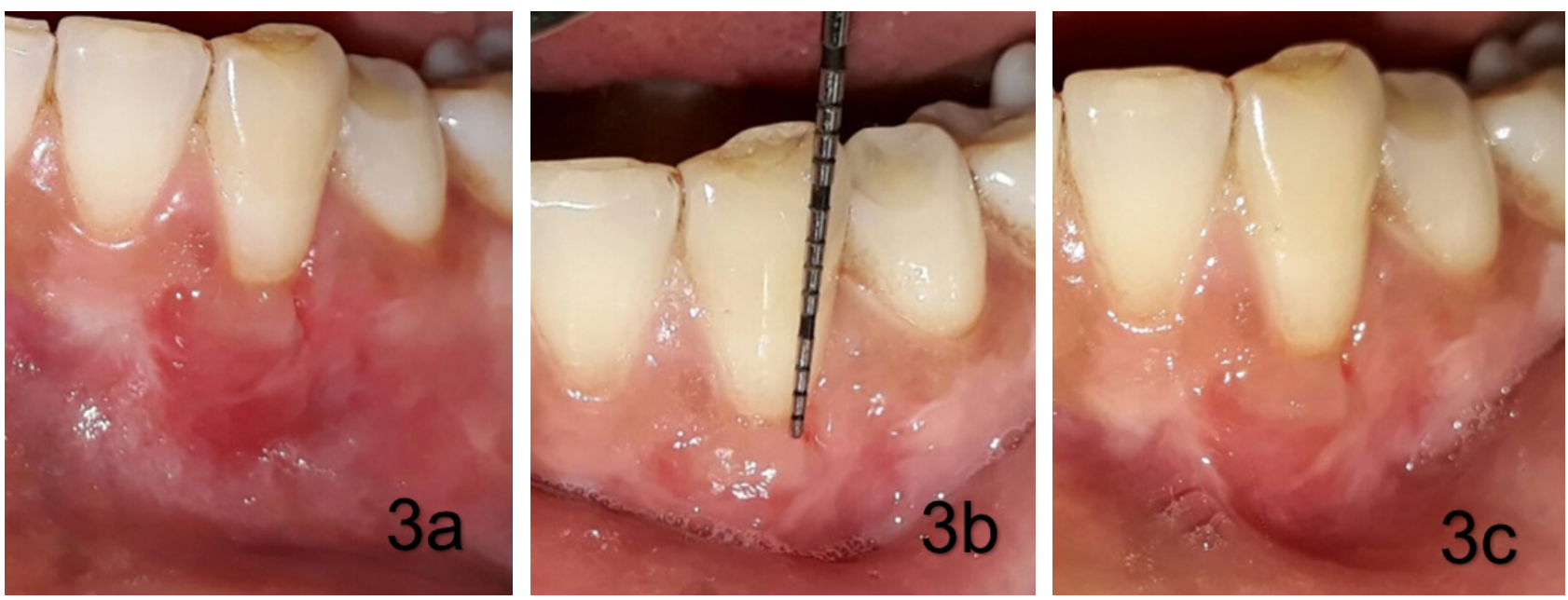

Figure 3a, 3b, 3c: Post-operative 1 month, 3 months and 6 months.

Surgical procedure: After proper isolation, the operative site was anesthetized using 2\% Lignocaine with 1:100,000 adrenaline. Modified surgical approach for isolated recession i.e. laterally moved, coronally advanced flap by Zucchelli5 was performed. The recipient site on 33 was prepared and donor site was planned from 32. A full thickness flap up to the mucogingival junction and then a partial thickness flap was raised by leaving marginal gingiva from 32 in order to slide the flap laterally and coronally to cover 33 (Figure 2a). The graft was secured with 4-0 non-resorbable silk suture and covered with Coe-Pak (Figure 2b, 2c).

Post-operative care: Analgesic (Ibuprofen $400 \mathrm{mg}$ ) three times a day for 2 days with $0.2 \%$ chlorhexidine digluconate mouth rinse for 4 weeks was prescribed. The patient was advised to follow post-operative hygiene instructions. The periodontal dressings and sutures were removed after 14 days of surgery. The post-operative evaluation was conducted at 1,3 and 6 months after surgery (Figure 3a, 3b, 3c).

\section{DISCUSSION}

The pedicle graft was the first periodontal plastic surgery procedure proposed in 1956 for root coverage. ${ }^{4}$ Pedicle grafts are based on the simple concept of moving donor tissue laterally to cover an adjacent defect. It provides sufficient aesthetic result but is less versatile than the connective tissue graft. The LFP is used widely and successfully to cover Miller class-I and class-II recession defects. ${ }^{6}$ It was first described as the "lateral sliding flap" by Grupe and Warren (1956). The procedure was then modified and named as the "laterally positioned flap". The "oblique rotational flap", the "rotation flap", and the "trans-positioned flap" are modifications in incision design. ${ }^{7}$ All these procedures have a common requirement of adequate width of attached gingiva prior to root coverage procedures. ${ }^{7}$

This case report describes the surgical procedure in which a LPF was used for root coverage in Miller class-I recession defect in the mandibular anterior area. We achieved 100\% 
root coverage at 3 months that was stable at 6 months follow up with uneventful healing at the donor site. The advantage of using this technique is no post-operative discomfort, good vascular supply and color matching with stable result. However, due to the unpredictability of this graft, it should be done with meticulous care, ideal situations and care in preparing the sites (both recipient and donor). Reports on the LPF surgical technique are quite dated. ${ }^{8}$ In the literature, the reported mean percentage of root coverage ranges between $34 \%$ and $82 \%$. Complete root coverage data are lacking and we could find only one study. ${ }^{7}$ Long term success of 3 years has been shown with $69 \%$ of root coverage with LPF by Caffesse and Guinard. ${ }^{9}$ Predictable and highly aesthetic results may be obtained with this simple technique with proper case selection. McFall ${ }^{10}$ reported success in 25 out of 27 cases with LPF. Zucchelli ${ }^{5}$ in 120 isolated gingival recession with modified surgical approach reported 97\% of the root surface was covered with soft tissue and 80\% defects showed complete root coverage after 1 year.

\section{CONCLUSION}

In LPF with minimal discomfort, good color match and harmony with adjacent tissue may be achieved for an isolated defect. So, to avoid complex procedure and for good harmonized gingival tissue we need to think pink and think lateral.

\section{ACKNOWLEDGEMENT}

Dr. Shivalal Sharma, Professor and Head, Department Of Periodontology and Oral Implantology, College of Dental Surgery, BP Koirala Institute of Health Sciences, Dharan, Nepal.

\section{REFERENCES}

1. Wennström JL. Mucogingival therapy. Ann Periodontol. 1996;1:671-701.

2. Tugnait A, Clerehugh V. Gingival recession-its significance and management. J Dent. 2001;29:381-94

3. Mohan M, Gupta V, Gupta B. Root coverage with laterally moved, coronally advanced flap (Zucchelli's technique). A case report. Rama Univ J Dent Sci. 2015;2(4):30-34.

4. Grupe J, Warren R. Repair of gingival defects by a sliding flap operation. J Periodontol. 1956;27:290-5.

5. Zucchelli G, Cesari C, Amore C, Montebugnoli L, De Sanctis M. Laterally moved, coronally advanced flap: a modified surgical approach for isolated recession-type defects. J Periodontol. 2004;75(12):1734-41.

6. Grupe HE. Modified technique for sliding flap operation. J Periodontol. 1966;37(6):491-5.

7. Roccuzzo M, Bunino M, Needleman I, Sanz M. Periodontal plastic surgery for treatment of localized gingival recessions: A systematic review. J Clin Periodontol. 2002;29:178-94.

8. Zucchelli G, Mounssif I. Periodontal plastic surgery. Periodontol 2000. 2015; 68:333-68.

9. Caffesse RG, Guinard EA. Treatment of localized gingival recessions - Part IV: results after 3 years. J Periodontol. 1980;51(3):167-70.

10. McFall WT Jr. The laterally repositioned flap-criteria for success. Periodontics. 1967;5(2):89-92. 